\title{
Surface-enhanced Raman Scattering (SERS) Substrate of Colloidal Ag Nanoparticles Prepared by Laser Ablation for Ascorbic Acid Detection
}

\author{
Teguh Endah Saraswati ${ }^{1}$, Yudha Pratama Putra ${ }^{1}$, Mohammad Rifqi Ihsan ${ }^{1}$, Isnaeni ${ }^{2}$, Yuliati Herbani2 ${ }^{*}$ \\ ${ }^{1}$ Department of Chemistry, Faculty of Mathematics and Natural Sciences, Sebelas Maret University, Jl. Ir. \\ Sutami 36A Surakarta 57126, Indonesia \\ ${ }^{2}$ Research Center for Physics, Indonesian Institute of Sciences, Jl Riset Gd 442 Kawasan Puspitek, \\ Tangerang Selatan 15314, Banten, Indonesia \\ *email: yuliati.herbani@lipi.go.id
}

Received February 4, 2018; Accepted April 30, 2018; Available online May 31, 2018

\begin{abstract}
Ag nanoparticles were synthesized by laser ablation using an Ag plate in distilled water. This method was performed using a laser with a wavelength of $532 \mathrm{~nm}$ and energy of $30 \mathrm{~mJ}$ for $60 \mathrm{~min}$. Ag nanoparticles successfully formed, confirmed by the selected area electron diffraction (SAED) which revealed four principal crystal planes of (111), (200), (220) and (311). The size distribution of $\mathrm{Ag}$ nanoparticles ranged from 5 to $40 \mathrm{~nm}$, as estimated from electron imaging observed by transmission electron microscope (TEM). Ascorbic acid was used as the analyte to test the characteristics of surface-enhanced Raman scattering (SERS) of colloidal Ag nanoparticles. The concentration of ascorbic acid (1.0, 0.5 and 0.25 wt\%) and incubation time ( 0 and $6 \mathrm{~h}$ ) were varied to determine the limit of detection and the effect of incubation time. The Raman scattering spectroscopy results showed that the colloidal Ag nanoparticle substrate improved the signals for detection of ascorbic acid.
\end{abstract}

Keywords: Laser Ablation, Nanoparticles, Silver, Ascorbic acid, SERS

\section{INTRODUCTION}

$\mathrm{Ag}$ nanoparticles have highly efficient and unique light absorption and distribution properties. The color of Ag nanoparticles depends on the size and shape of the particles. In general, the peak absorbance value of $\mathrm{Ag}$ nanoparticles is appeared at a wavelength of 400-500 nm, and as the particle size increases, the absorbance peak progressively shifts to the right (Kamat, Flumiani, \& Hartland, 1998). Colloidal nanoparticles produce colors due to localized surface plasmon resonances (LSPRs). LSPR is an optical phenomenon that occurs when a light wave trapped on a conductive nanoparticle smaller than the light wavelength. This phenomenon results in the interaction between light waves and surface electrons in the nanoparticle (Petryayeva \& Krull, 2011). The wavelength of the LSPR excitation can be used to determine the size of the nanoparticle (Haiss, Thanh, Aveyard, \& Fernig, 2007). The size of the nanoparticles can thus be predicted through their specific LSPR wavelengths (Mulfinger et al., 2007).

Ag nanoparticles have stable properties and potential in various applications, such as in anti-viral compounds (Sharma, Frontiera, Henry, Ringe, \& Van Duyne, 2012), drug delivery compounds (Dreaden, Mackey, Huang, \& Kang, 2011), therapy (Austin, MacKey, Dreaden, \& El-Sayed, 2014) and surface-enhanced Raman spectroscopy (SERS) (Kneipp, Kneipp, Wittig, \& Kneipp, 2010).

Nanoparticles synthesis can be performed by top-down or bottom-up methods. Bottom-up techniques, such as chemical methods, have some limitations, e.g., the presence of impurities, resulting in excess precursor residues or unexpected by-products, can lead to decreased control of the size and shape and low stability of the synthesized nanoparticles. Among the various methods developed to overcome these problems, physical methods of nanoparticle synthesis, such as laser ablation, are classified as topdown techniques. Synthesis of nanoparticles with the laser ablation method can be conducted in water or an organic medium to obtain colloidal nanoparticles (Amendola \& Meneghetti, 2009).

$\mathrm{Ag}$ nanoparticles have various applications. Colloidal Ag nanoparticles have great potential in the development of methods for detecting specific compounds in an unknown material, including SERS substrates (Guicheteau et al., 2013) to increase the sensitivity in detecting an analyte molecule in 
a sample. Raman scattering is a form of nonelastic interaction between light and material and has become an analytical technique for material identification (Fazio, Trusso, \& Ponterio, 2013). Since its discovery in 1970, SERS has continued to develop in both research and industry fields. SERS is a signal enhancement phenomenon in Raman spectroscopy caused by analytical interaction with metal nanoparticles, such as $\mathrm{Ag}$ nanoparticles.

The SERS effect of Ag nanoparticle colloids can be utilized in the detection of an organic molecules (Fazio et al., 2013), such as ascorbic acid or vitamin C. Ascorbic acid is an essential compound in the human body, and is required for collagen formation, enzyme activation, and antioxidant properties (Rahmawati \& Bundjali, 2012). It can be identified using a Raman spectrophotometer. The Raman spectra of ascorbic acid have several major peaks, identified by Raman shifts at $825,1299,1692$ and $3480 \mathrm{~cm}^{-1}$. These Raman spectra results were obtained using laser wavelengths of $532 \mathrm{~nm}$ and $488 \mathrm{~nm}$ (Berg, 2014). Therefore, this study investigated the utilization of the SERS activity of colloidal Ag nanoparticles prepared by laser ablation method for the detection of ascorbic acid.

\section{EXPERIMENTAL SECTION}

Ag nanoparticles were synthesized using the laser ablation method in a liquid medium by referring to a previous study (Amendola \& Meneghetti, 2009). Laser ablation was performed on a $99.9 \%$ silver metal plate (ANTAM) using Nd:YAG nanosecond laser (Q-Smart 850, Quantel) at a wavelength of 532 $\mathrm{nm}$, frequency of $10 \mathrm{~Hz}$, ablation time of $1 \mathrm{~h}$, and distilled water as the solvent. Laser energy of $30 \mathrm{~mJ}$ measured by a laser power/energy meter (LabMax-Top, Coherent) was used with ablation set up shown in Figure 1. After synthesis, Ag nanoparticles produced were studied by transmission electron microscopy (TEM FEI Tecnai G2 20 S-Twin) with the accelerating voltage of $200 \mathrm{kV}$ for imaging and electron diffraction analysis.

The UV-Vis spectrum was obtained using a UV-Vis spectrophotometer (MayaPro 2000, Ocean Optics). The Raman spectrum test was carried out using a diode pumped solid state (DPSS; Elforlight) with a wavelength of around $532 \mathrm{~nm}$ and a detector (Maya2000,
Ocean Optics) with the set-up as shown in Figure 2. Ascorbic acid solutions of 1.0, 0.5 and $0.25 \mathrm{wt} \%$ were prepared as analyte sample. L-ascorbic acid $\left(\mathrm{C}_{6} \mathrm{H}_{8} \mathrm{O}_{6}, 99 \%\right.$, Sigma-Aldrich) was used in this study without any prior treatment.

\section{RESULTS AND DISCUSSION}

The colloidal Ag nanoparticles used in this study were obtained from laser ablation using $\mathrm{Nd}$ :YAG laser. The process of synthesizing Ag nanoparticles using laser ablation methods, shown in Figure 3, involved several stages, such as evaporation, nucleation, nuclei growth and coalescence, and nanoparticles growth (Amendola \& Meneghetti, 2009).

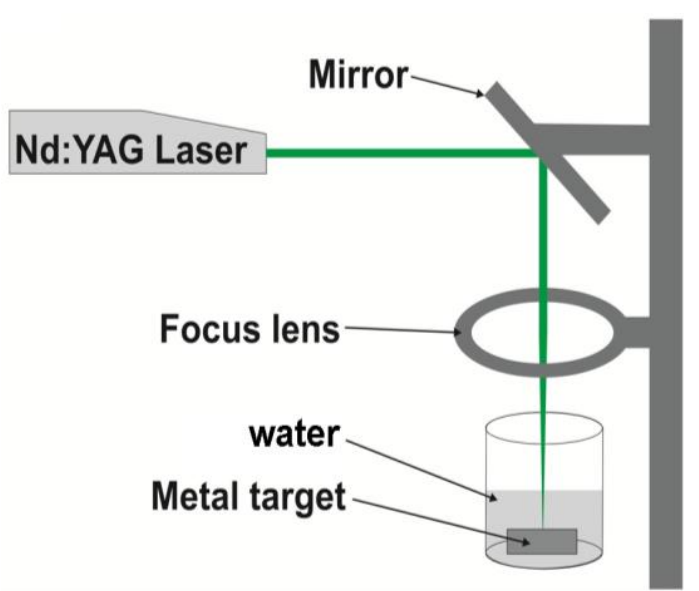

Figure 1. Experimental setup in $\mathrm{Ag}$ nanoparticle synthesis by pulse laser ablation

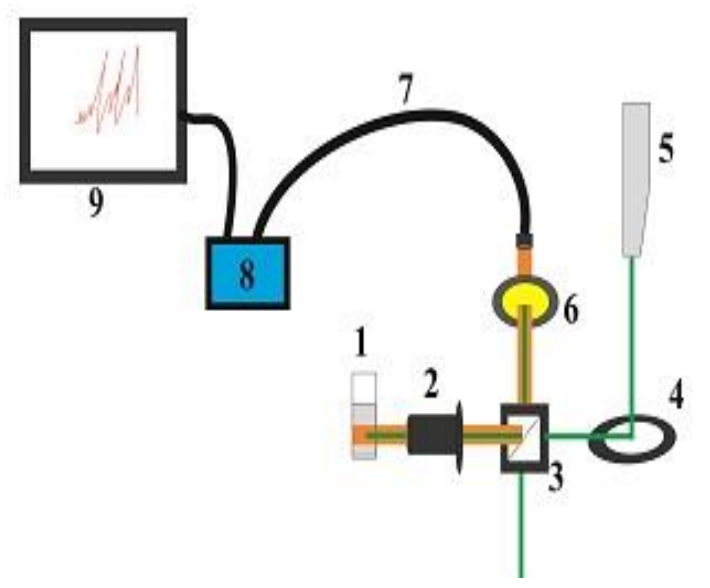

Figure 2. The experimental setup in Raman scattering study: cuvette as sample place (1); objective lens (20x) (2); beam splitter (3); optical mirror (4); DPSS laser in wavelength of $530.421 \mathrm{~nm}(\mathbf{5})$; notch laser filter (6); optical fiber (7); spectrophotometer (Ocean Optics Maya 2000) (8) and computer (9). 


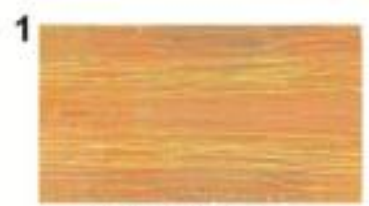

Vaporation
2

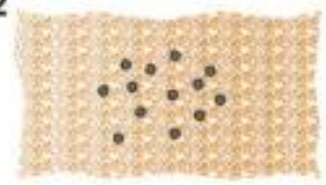

Nucleation
3

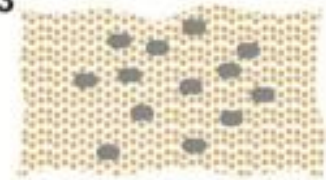

Nuclei growth
4

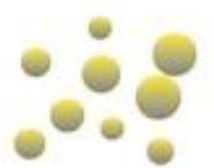

Final Nanoparticles

Figure 3. The stages of nanoparticle formation in laser ablation synthesis processing.

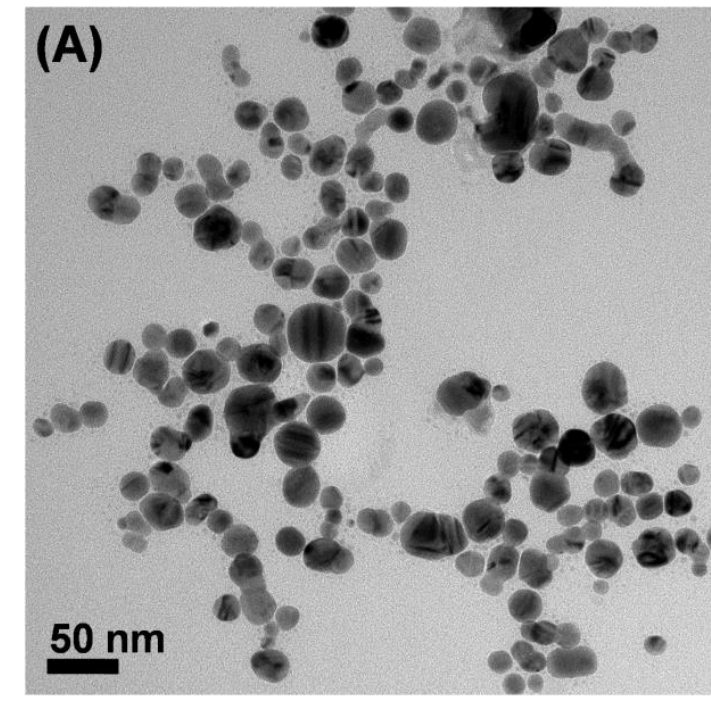

(B)

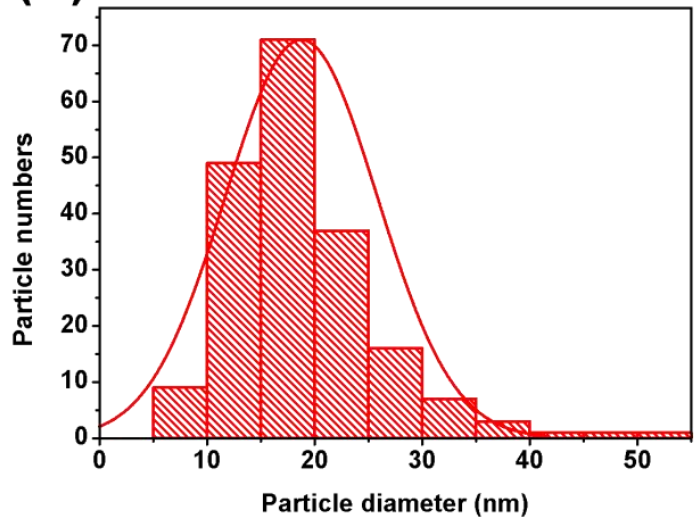

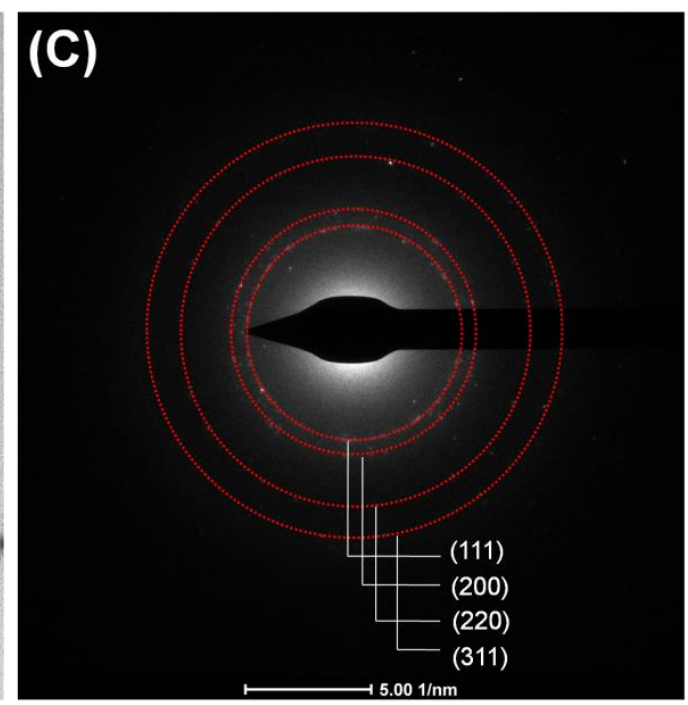

(D)

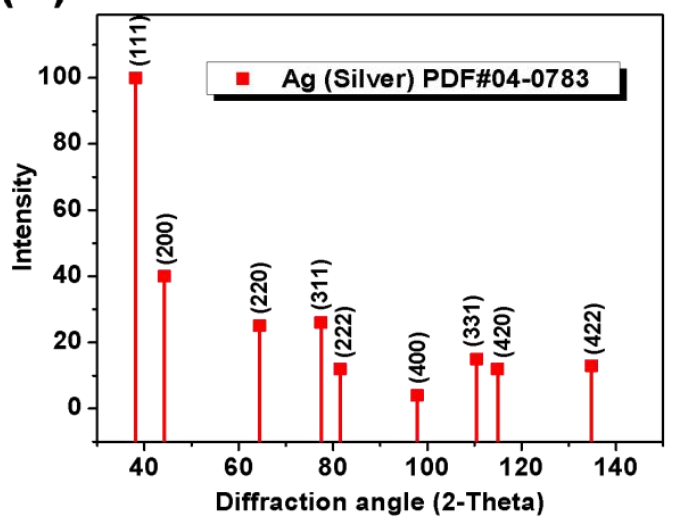

Figure 4. Ag nanoparticles imaging taken by transmission electron microscope (TEM) (A); the histogram of diameter of Ag nanoparticles (B); selected area electron diffraction (SAED) of the Ag nanoparticles in the represented TEM image with diffracted planes $(\mathbf{C})$; confirmed to the X-ray diffraction database of $\mathrm{Ag}$ (silver) (D).

To confirm the success of the $\mathrm{Ag}$ nanoparticles formation in colloidal sample produced after laser ablation, we used the transmission electron microscope to observe not only the particles size but also the electron diffraction of the particles. Figure 4 shows transmission electron microscope (TEM) imaging and the size distribution of the observed nanoparticles (Figure 4(A) and 4(B)); and the selected area electron diffraction (SAED) of the represented TEM image noted by diffracted planes matched with the X-ray diffraction database of $\mathrm{Ag}$ (silver) (Figure $\mathbf{4}(\mathrm{C})$ and $\mathbf{4 ( D )})$.

According to the TEM analysis shown in Figure 4(A) and 4(B), the colloidal sample produced after laser ablation was the $\mathrm{Ag}$ particles growth in a spherical shape of nanometer size. The histogram presented in Figure 4(B) shows that the Ag nanoparticles have a diameter range of $10-30 \mathrm{~nm}$.

The particles produced in laser ablation were confirmed as Ag particles studied from the selected area electron diffraction (SAED), 
as shown in Figure 4(C) and 4(D). Four diffraction ring observed in the SAED picture (Figure 4(C)), represented to the four principal diffracted planes of Ag (111), (200), (220), and (311) according to the X-ray diffraction database of Ag (Figure 4(D)). We confirmed these four crystal planes by calculating the lattice spacing $(d)$ interpreted from the SAED ring pattern with a camera length of $680 \mathrm{~mm}$, and electron wavelength of $0.0027 \mathrm{~nm}$ (at $200 \mathrm{kV}$ accelerating voltage). The calculated $d$ spacings of the four planes were 0.2359, $0.2051,0.1448$ and $0.1219 \mathrm{~nm}$ for crystal planes of (111), (200), (220), and (311), respectively, which were close to the $d$ spacing of $\mathrm{Ag}$ (silver) in X-ray diffraction database.

The confirmation of $\mathrm{Ag}$ nanoparticles formation was also performed by UV-Vis spectrophotometer to study their plasmon excitation spectra, as presented in Figure 5. The synthesized colloidal Ag nanoparticles produced after laser ablation was in a greenish fluid, shown as the inset in Figure 5. The UVVis spectra analysis showed that the colloidal Ag nanoparticle exhibited LSPR spectra with a peak wavelength of $412 \mathrm{~nm}$. This result is consistent with previous research (Bakir, 2011) stating that $\mathrm{Ag}$ nanoparticles exhibit LSPR excitation wavelengths between 400 and 500 nm. Moreover, since the obtained peak was located at a wavelength of $412 \mathrm{~nm}$, it can be predicted that the colloidal $\mathrm{Ag}$ nanoparticles have a diameter less than $40 \mathrm{~nm}$ (Mulfinger et al., 2007) which are in a good agreement with the particle size distribution estimated from the imaging analysis observed by TEM, as shown in Figure 4(B).

After $\mathrm{Ag}$ nanoparticles formation was well confirmed, the study was continued to the Raman scattering study. The colloidal Ag nanoparticles obtained were used as the SERS substrate for the detection of ascorbic acid. The ascorbic acid solution with $\mathrm{Ag}$ nanoparticles was tested using a Raman spectrophotometer, and the results revealed that the Raman scattering was more powerful when $\mathrm{Ag}$ nanoparticles were added to the ascorbic acid solution.

A schematic of the Raman scattering test shown in Figure 6 illustrates a comparison of ascorbic acid detection with and without $\mathrm{Ag}$ nanoparticle addition. Raman scattering of ascorbic acid with $\mathrm{Ag}$ nanoparticles addition revealed more intense Raman scattering compared to those without $\mathrm{Ag}$ nanoparticles addition. Ascorbic acid will be adsorbed on the surface of $\mathrm{Ag}$ nanoparticles resulting in enhanced Raman scattering.

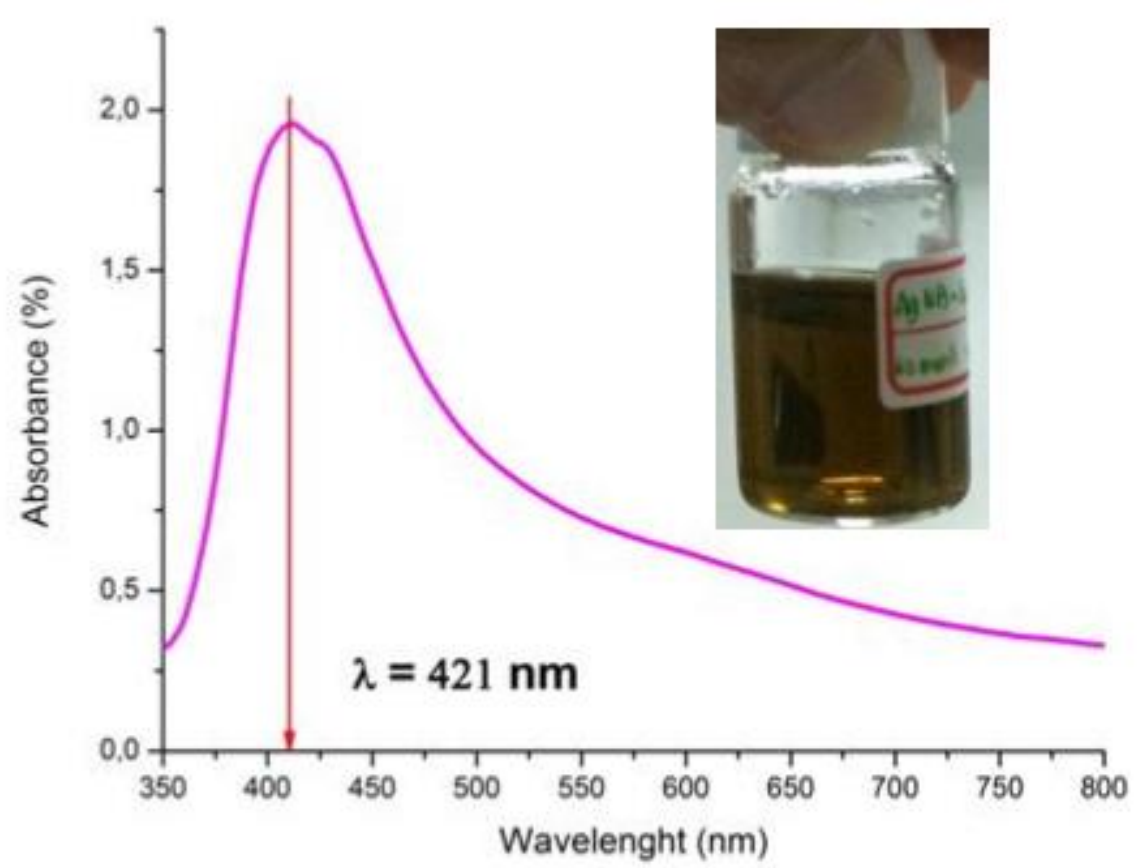

Figure 5. UV-Vis spectra of Ag nanoparticles after laser ablation; Inset: colloidal Ag nanoparticles produced by laser ablation. 


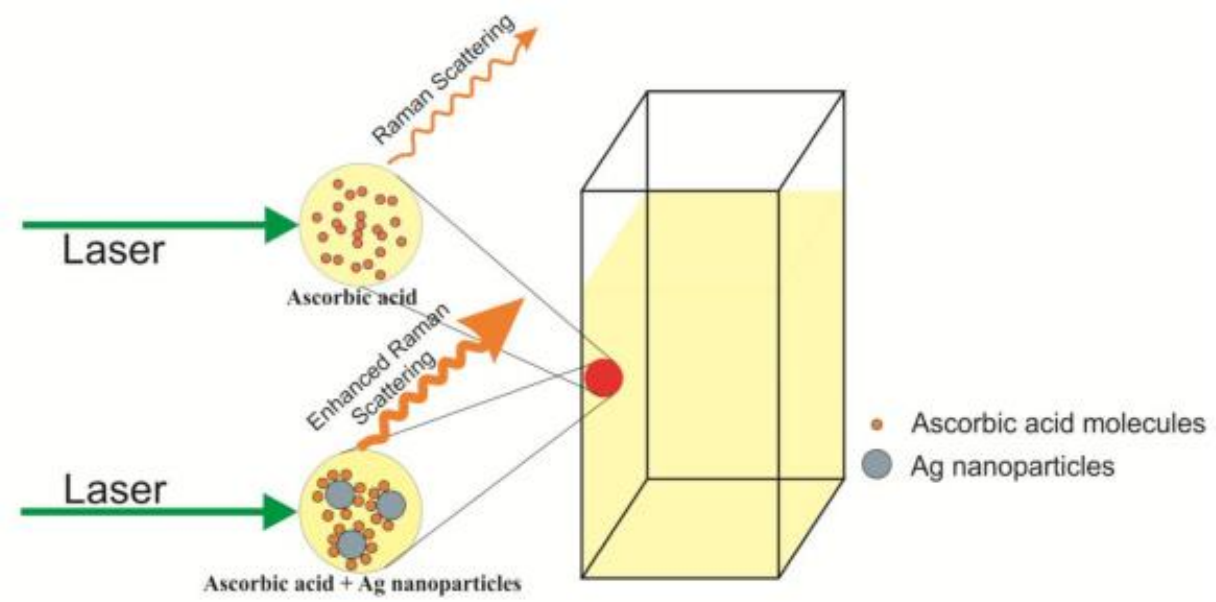

Figure 6. Illustration of the SERS effect due to the addition of Ag nanoparticles in ascorbic acid solution.
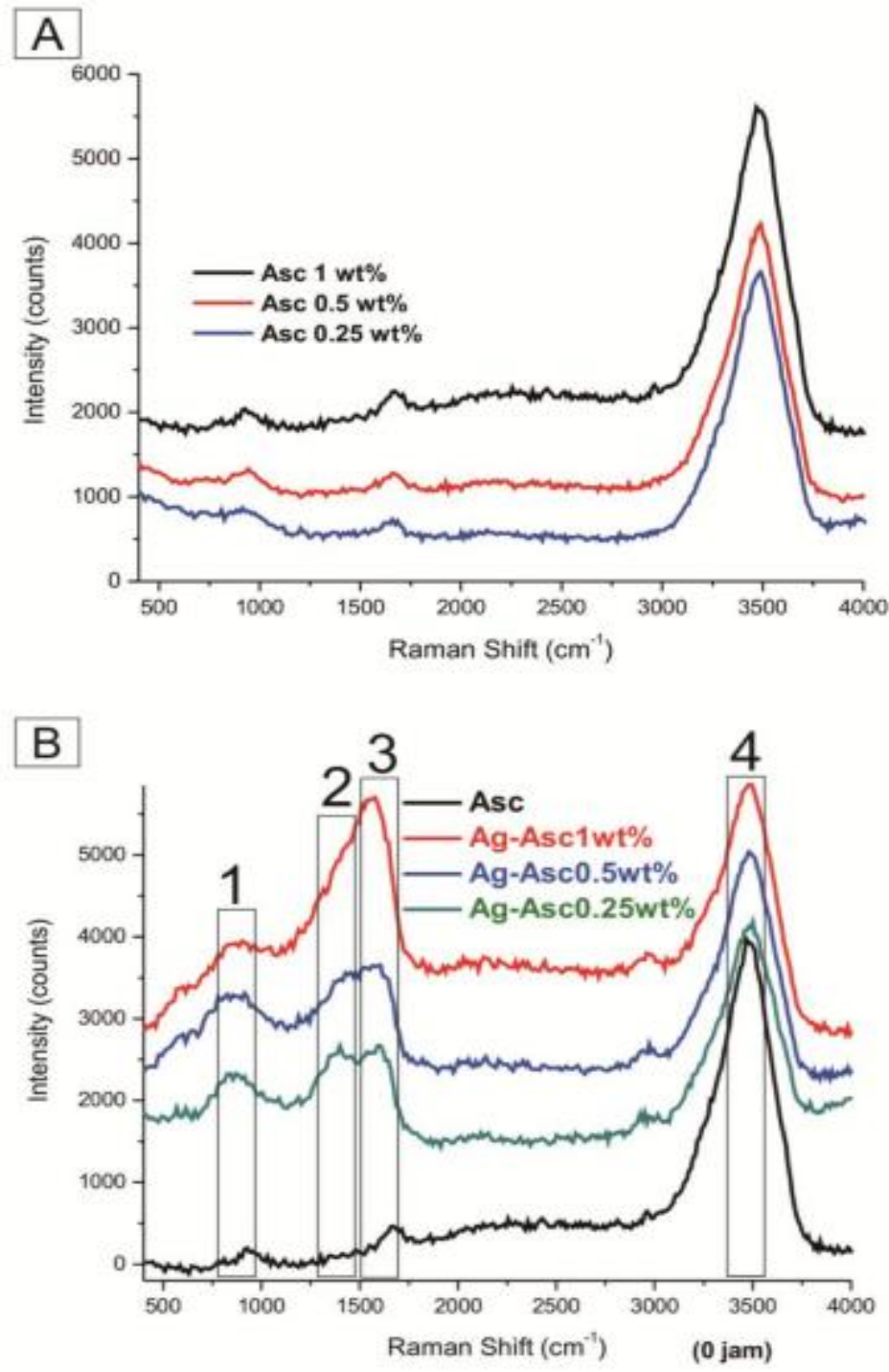

Figure 7. Raman shift spectra of ascorbic acid at various concentrations without (A) and with (B) colloidal nanoparticles added (Asc $=$ ascorbic acid; $\mathrm{Ag}=\mathrm{Ag}$ nanoparticles; numbers $1-4$ indicate peaks presented in Table 1). 
Figure 7(A) shows the Raman shift spectra of the ascorbic acid solution at different concentrations. Raman shifts of ascorbic acid with a concentration of 1.0, 0.5 and $0.25 \mathrm{wt} \%$ exhibit almost similar peaks. The peak value of each ascorbic acid solution has an almost similar value, i.e., 825 , 1299, 1692,2915 and $3480 \mathrm{~cm}^{-1}$; these values are similar to those obtained in a previous study (Berg, 2014). The highest peak in the range of $\sim 3400 \mathrm{~cm}^{-1}$ was identified as the peak of the distilled water solvent. Figure 7(B) shows the Raman shift spectra of a solution of ascorbic acid at different concentrations with the addition of colloidal Ag nanoparticle colloids. The colloidal Ag nanoparticles were added at a 1:1 volume ratio of $\mathrm{Ag}$ nanoparticles and ascorbic acid solution for all ascorbic acid concentrations. The peak intensity of 1,2 , and 3 in the spectra shown in Figure 7(B) was significantly higher than the peak intensity of the spectra shown in Figure $\mathbf{7 ( A )}$. This concludes that the addition of colloidal $\mathrm{Ag}$ nanoparticles successfully increased the ascorbic acid peaks. The observed peaks in the Raman shift spectra are shown in Table 1.

Based on the spectra results, there is an increase in peak intensity after addition of the Ag nanoparticles. In the ascorbic acid sample without $\mathrm{Ag}$ nanoparticles, the peak location is not clearly visible, and after addition of the Ag nanoparticles, the ascorbic acid peaks appeared with different intensities at various ascorbic acid concentrations. Table $\mathbf{1}$ shows the increases of the peak intensity observed in the Raman spectra where the increase of the peak intensity reached 3 to 20 times from the initial intensity value. The significant increase of peak intensity clearly shows the Raman shift values before and after addition of $\mathrm{Ag}$ nanoparticles, and this is referred to as the SERS phenomenon.

Furthermore, the effect of the interaction duration of Ag nanoparticles and ascorbic acid compounds was also studied. This was done through an incubation process of the ascorbic acid solution and colloidal nanoparticle mixture in a bottle at room temperature for $6 \mathrm{~h}$. The incubation effect was tested for ascorbic acid detection at concentration $0.25 \mathrm{wt} \%$ with colloidal Ag nanoparticle added, as shown in Figure 8 .

As shown in Figure 8, the peaks of the Raman signals from the mixture of ascorbic acid $(0.5 \mathrm{wt} \%)$ and $\mathrm{Ag}$ nanoparticle at incubation times of $0 \mathrm{~h}$ and $6 \mathrm{~h}$ were all matched to each other at the same location Raman shift. Both spectra of ascorbic acid with addition of colloidal Ag nanoparticles have Raman signals at $825, \sim 1420$, and $\sim 1560 \mathrm{~cm}^{-1}$ (Raman characteristic for ascorbic acid) that are more intense than the spectra in the case without Ag nanoparticles. However, when comparing the spectra with incubation times of 0 and $6 \mathrm{~h}$, the intensities of the peaks in the Raman signal were not significantly different. The results suggest that the effect of the incubation duration is not significant; in other words, the addition of colloidal $\mathrm{Ag}$ nanoparticles can directly increase the Raman signal intensity with no an additional treatment time.

Table 1. Raman shift spectra peaks of ascorbic acid with colloidal Ag nanoparticles at various ascorbic acid concentrations.

\begin{tabular}{|c|c|c|c|c|c|c|}
\hline \multirow{2}{*}{$\begin{array}{c}\text { Peak } \\
\text { number }\end{array}$} & \multicolumn{4}{|c|}{ Raman shift $\left(\mathrm{cm}^{-1}\right)$ and the peak intensity } & \multirow{2}{*}{$\begin{array}{l}\text { Ref. } \\
\text { (Berg, } \\
\text { 2015) }\end{array}$} & \multirow[b]{2}{*}{ Signal } \\
\hline & Asc & $\begin{array}{c}\text { Ag-Asc } 0,25 \\
\text { wt } \%\end{array}$ & $\begin{array}{l}\text { Ag-Asc } 0,5 \\
\text { wt } \%\end{array}$ & Ag-Asc $1 \mathrm{wt} \%$ & & \\
\hline 1 & $\begin{array}{c}810,46 \\
(\uparrow 108,33)\end{array}$ & $\begin{array}{l}825,32 \\
(\uparrow 549)\end{array}$ & $\begin{array}{c}825,32 \\
(\uparrow 683,33)\end{array}$ & $\begin{array}{l}825,32 \\
(\uparrow 312)\end{array}$ & $825 \mathrm{~cm}^{-1}$ & SERS \\
\hline 2 & (1) & $\begin{array}{l}1385,49 \\
(\uparrow 545)\end{array}$ & $\begin{array}{c}1427,09 \\
(\uparrow 967,33)\end{array}$ & $\begin{array}{c}\sim 1420 \\
(\uparrow \sim 1500)\end{array}$ & $1299 \mathrm{~cm}^{-1}$ & SERS \\
\hline 3 & $\begin{array}{l}1659 \\
(\uparrow 94)\end{array}$ & $\begin{array}{c}1591,46 \\
(\uparrow 1170,67)\end{array}$ & $\begin{array}{l}1564,29 \\
(\uparrow 1100)\end{array}$ & $\begin{array}{c}1577,88 \\
(\uparrow 1826,67)\end{array}$ & $1692 \mathrm{~cm}^{-1}$ & SERS \\
\hline 4 & 3479 & 3479,08 & 3479,08 & 3479,08 & $3480 \mathrm{~cm}^{-1}$ & $\begin{array}{c}\text { Distilled } \\
\text { water }\end{array}$ \\
\hline
\end{tabular}

Note: $\uparrow$ indicates an increase in the peak intensity (in counts unit) 


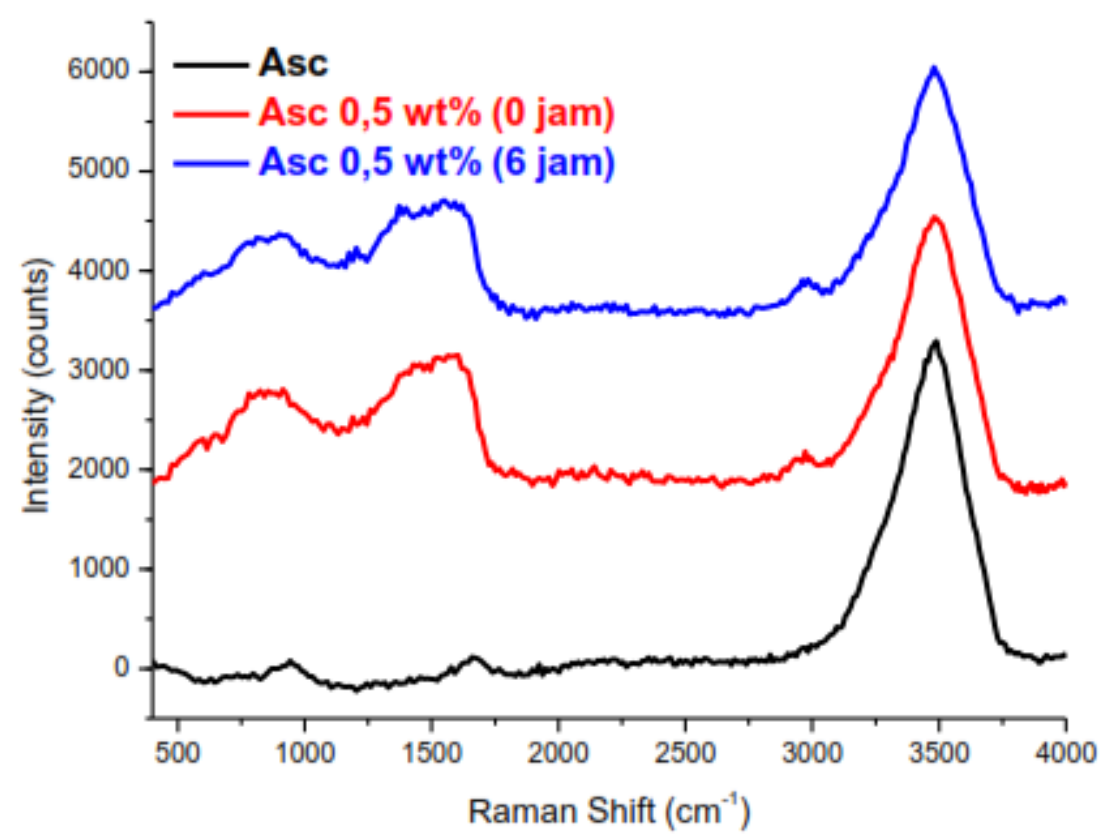

Figure 8. Raman shift spectra of the interaction of ascorbic acid $(0.5 \mathrm{wt} \%)$ with added $\mathrm{Ag}$ nanoparticles for 0 and $6 \mathrm{~h}$ incubation time.

\section{CONCLUSIONS}

$\mathrm{Ag}$ nanoparticles were synthesized by laser ablation with an excitation wavelength of at $412 \mathrm{~nm}$. Colloidal Ag nanoparticles increased the intensity of ascorbic acid detection signals by three- to twenty-fold, as shown by Raman spectrometer measurements. However, the incubation duration of $\mathrm{Ag}$ nanoparticles and ascorbic acid solution mixture did not have a significant effect on the increase in the signal intensity of ascorbic acid detection. In general, we concluded that colloidal $\mathrm{Ag}$ nanoparticles synthesized by the laser ablation method were potentially applied as a substrate for detection of ascorbic acid analytic compounds more sensitively and quickly using Raman spectrophotometry.

\section{ACKNOWLEDGEMENTS}

This work was equally supported by Grants-inAid Research from the Ministry of Research, Technology and Higher Education of Republic Indonesia under project No. 474/UN27.21/ PP/2018 and from Dana Kegiatan Penelitian Unggulan Kedeputian IPT - LIPI Tahun 2018.

\section{REFERENCES}

Amendola, V., \& Meneghetti, M. (2009). Laser ablation synthesis in solution and size manipulation of noble metal nanoparticles. Physical Chemistry
Chemical Physics : PCCP, 11(20), 38053821. https://doi.org/10.1039/b900654k

Austin, L. A., MacKey, M. A., Dreaden, E. C., \& El-Sayed, M. A. (2014). The optical, photothermal, and facile surface chemical properties of gold and silver nanoparticles in biodiagnostics, therapy, and drug delivery. Archives of Toxicology, 88(7), 1391-1417. https://doi.org/10.1007/s00204-0141245-3

Bakir. (2011). Pengembangan Biosintesis Nanopartikel Perak Menggunakan Air Rebusan Daun Bisbul (Diospyros blancoi) untuk Deteksi Ion Tembaga (II) dengan Metode Kolorimetri. Bachelor Thesis (In Indonesia). Program Studi Fisika, Fakultas Matematika Dan Ilmu Pengetahuan Alam, UI, Depok., (Ii).

Berg, R. W. (2014). Investigation of L (+)Ascorbic acid with Raman spectroscopy in visible and UV light. Applied Spectroscopy Reviews, 50(3), 193-239. https://doi.org/10.1080/05704928.2014.9 52431

Dreaden, E., Mackey, M., Huang, X., \& Kang, B. (2011). Beating cancer in multiple ways using nanogold. Chemical Society Reviews, 40(7), 3391-3404. https://doi.org/10.1039/c0cs00180e

Fazio, E., Trusso, S., \& Ponterio, R. (2013). Surface-enhanced Raman scattering study of organic pigments using silver and gold 
nanoparticles prepared by pulsed laser ablation. Applied Surface Science, 272, 36-41.

https://doi.org/10.1016/j.apsusc.2012.02. 070

Guicheteau, J.A., Farrell, M.E., Christesen, S.D., Fountain III, A.W., Pellegrino, P.M., Emmons, E.D., Tripathi, A., Wilcox, P. and Emge, D. (2013). Surfaceenhanced Raman scattering (SERS) evaluation protocol for nanometallic surfaces. Applied Spectroscopy, 67(4), 396-403. https://doi.org/10.1366/1206846

Haiss, W., Thanh, N., Aveyard, J., \& Fernig, D. (2007). Determination of size and concentration of gold nanoparticles from UV- Vis spectra. Analytical Chemistry. $79(11)$, 4215-4221. https://doi.org/10.1021/ac0702084

Kamat, P. V, Flumiani, M., \& Hartland, G. V. (1998). Picosecond Dynamics of Silver Nanoclusters. Photoejection of Electrons and Fragmentation. The Journal of Physical Chemistry B, 102(17), 31233128. https://doi.org/10.1021/jp980009b

Kneipp, J., Kneipp, H., Wittig, B., \& Kneipp,
K. (2010). Novel optical nanosensors for probing and imaging live cells. Nanomedicine: Nanotechnology, Biology and Medicine, 6(2), 214-226. https://doi.org/10.1016/j.nano.2009.07.00 9

Mulfinger, L., Solomon, S. D., Bahadory, M., Jeyarajasingam, A. V., Rutkowsky, S. a., \& Boritz, C. (2007). Synthesis and Study of Silver Nanoparticles. Journal of Chemical Education, 84(2), 322-325. https://doi.org/10.1021/ed084p322

Petryayeva, E., \& Krull, U. (2011). Localized surface plasmon resonance: nanostructures, bioassays and biosensing - a review. Analytica chimica acta, 706(1), 8-24. https://doi.org/10.1016/j.aca.2011.08.020

Rahmawati, S., \& Bundjali, B. (2012). Kinetics of the oxidation of vitamin C. Indonesian Journal of Chemistry, 12(3), 291-296.

Sharma, B., Frontiera, R. R., Henry, A.-I., Ringe, E., \& Van Duyne, R. P. (2012). SERS: Materials, applications, and the future. Materials Today, 15(15), 16-25. https://doi.org/10.1016/S13697021(12)70017-2 